\title{
INTERFERÊNCIA DO PROCESSO dE COAGULAÇÃO NA REMOÇÃo DE COMPOSTOS ORGÂNICOS CAUSADORES DE GOSTO E ODOR EM ÁGUAS DE ABASTECIMENTO MEDIANTE A APLICAÇÃo DE CARVÃo ATIVADO EM PÓ
}

\author{
COAGULATION PROCESS AND ITS INTERFERENCE ON THE TASTE AND ODOR \\ REMOVAL IN DRINKING WATER TREATMENT BY POWDERED ACTIVATED \\ CARBON APPLICATION
}

\section{RESUMO}

O carvão ativado em pó (CAP) tem sido empregado no tratamento de águas de abastecimento para a solução de problemas de gosto e odor, podendo sua aplicação ser efetuada antes ou depois da mistura rápida ou juntamente com o coagulante. Tendo em vista as dúvidas existentes entre a interferência do processo de coagulação na eficiência do processo de adsorção, foram conduzidos ensaios de jarros simulando-se diversos cenários de aplicação de dosagem de coagulante e CAP. Concluiu-se que, para as mesmas dosagens de CAP e coagulante aplicadas, independentemente do seu ponto de aplicação, não foram observadas diferenças significativas na remoção de compostos causadores de gosto e odor, o que indica que, sob as condições testadas, o ponto de aplicação de CAP, antes ou depois da aplicação do coagulante, possui muito pouca importância na eficiência do processo de adsorção.
\end{abstract}

MARGARIDA MARCHETTO

Pesquisadora Pós-Doutoranda do Departamento de Engenharia Hidráulica e Sanitária da Escola Politécnica da

Universidade de São Paulo

SIDNEY SECKLER FERREIRA FILHO

Engenheiro Civil pela EPUSP (1988). Mestre (1993) e Doutor (1996) em Engenharia Civil pela EPUSP. Professor Associado do Departamento de Engenharia Hidráulica e Sanitária da Escola Politécnica da Universidade de São Paulo
PALAVRAS-CHAVE: Tratamento de água, adsorção, gosto e odor, carvão ativado em pó.

\begin{abstract}
Powered Activated Carbon (PAC) has been widely used in Water Treatment Plants with the purpose of minimizing taste and odor problems in drinking water. Its application can be done immediately before or after coagulant application or in parallel with it. To look into possible interferences of the coagulation process in the adsorption process, an experimental investigation was carried out by means of jar tests, with the purpose of simulating different case scenarios of $P A C$ and coagulant application. For the same PAC type and coagulant dosage, regardless of the application point, it was not observed any significant differences in the removal of taste and odor compounds, thus indicating that under the tested conditions the PAC application point has a much lower importance than the initially expected in adsorption processes.
\end{abstract}

KEYWORDS: Drinking water treatment, adsorption, taste and odor compounds, powdered activated carbon.

\section{INTRODUÇÃO}

O crescimento populacional em Regiōes Metropolitanas de forma desordenada e sem controle tem criado um enorme problema de engenharia ambiental. Em países em desenvolvimento, grande parte das águas residuárias são dispostas em rios e lagos sem tratamento devido, e a maioria destes também são utilizados como mananciais para abastecimento público.

A presença de algas em concentraçôes elevadas em mananciais utilizados para abastecimento público causa sérios problemas em Estaçôes de Tratamento de Água, sendo que a eventual presença de toxinas e compostos orgânicos causadores de gosto e o odor liberados por algas e demais microrganismos são os mais relevantes.

Os métodos mais comumente usados para a remoção de gosto e odor são por processos de adsorção em carvão ativado em pó e granular e oxidação química mediante o emprego do cloro, permanganato de potássio, ozônio e peroxônio (ozônio e peróxido de hidro- gênio). Todos os métodos empregados para a remoção de MIB e geosmina têm limitações significativas. No tocante aos processos de oxidação química, tanto o cloro como o permanganato de potássio apresentam baixas eficiências de remoção de MIB e geosmina, sendo o ozônio e peroxônio os agentes oxidantes mais efetivos, embora de maior custo. A utilização do cloro e dióxido de cloro tem-se mostrado eficiente para remoção de alguns tipos de sabor e odor, mas não para a remoção de MIB e geosmina (Lalezary et al, 1986a). 
Por sua vez, a eficiência dos processos de adsorção de MIB e geosmina por intermédio do uso do CAP e carvão ativado granular (CAG) é menor quando comparados com outros compostos orgânicos que geram gosto e odor (Lalezary et al, 1986b). Além disso, a presença de compostos orgânicos naturais (CONs) e oxidantes tais como cloro e cloraminas reduz a eficiência dos processos de adsorção na sua remoção (Lalezary et al,1986b; Lalezary et al, 1988; Nerenberg et al, 2000; Ferreira Filho, 2001).

Em 1998, Gillogly relatou que o CAP era freqüentemente aplicado em ETAs sem uma perfeita compreensão de como outros produtos químicos poderiam afetar na adsorção dos compostos. $\mathrm{No}$ entanto, Glaze et al (1990) e Ferreira Filho $(2000,2001)$ verificaram que a capacidade de adsorçâo do composto MIB por CAP foi reduzida quando combinado com cloro livre, tendo-se obtido eficiência ótima quando o contato entre CAP e cloro foi reduzido ou mesmo eliminado.

Em função da possível interferência dos agentes oxidantes aplicados na água bruta no processo de adsorção de MIB e geosmina, conforme documentado na literatura, Ferreira Filho (2001) executou ensaios cinéticos de adsorção objetivando quantificar o grau de interferência da aplicação de ambos agentes oxidantes e os meios adsorvedores. Os ensaios foram conduzidos em equipamento de "jar-test", tendo-se avaliado a ação do cloro e do permanganato de potássio, separadamente. $\mathrm{O}$ autor testou seis CAPs de diferentes fabricantes e verificou que a aplicação de CAP na captação era o local mais adequado.

Em ETAs convencionais (Figura 1), os pontos mais indicados para adição de CAP são na captação, na entrada da ETA, que pode ser a montante ou a jusante da mistura rápida ou juntamente com o coagulante e, eventualmente, no canal de água decantada a montante dos filtros (Ferreira Filho, 1996).

O CAP aplicado na água bruta objetiva um aumento do tempo de contato deste com os compostos orgânicos causadores de gosto e odor para, posteriormente, ser incorporado ao hidróxido metálico formado durante o processo de coagulação para remoção subseqüente nos decantadores e, eventualmente, no sistema de filtração (Najm et al, 1990).

$A$ adição de CAP diretamente na água bruta tem a vantagem de permitir maior tempo de contato entre ambos, no entanto, há a possibilidade do CAP adsorver CONs e estes diminuírem a quantidade de sítios de adsorção disponíveis para a remoção dos compostos orgânicos causadores de gosto e odor. Teoricamente, a remoção de gosto e odor deveria ser maior para a situação em que o CAP é adicionado nas fases posteriores do processo de tratamento em que os CONs são removidos no processo de coagulaçãa.

No entanto, sabe-se que a coagulação possui maior efetividade na remoção de CONs com maior peso molecular, podendo não remover $\mathrm{CON}$ com peso molecular reduzido, possibilitando que estes possam ser adsorvidos pelo CAP e competirem pelos mesmos sítios de adsorção responsáveis pela remoção dos compostos causadores de gosto e odor.

Para muitas ETAs, a aplicação do CAP diretamente na água bruta é muito difícil, seja pela inexistência de instalaçôes adequadas, dosagem e controle do CAP junto à captação, seja pelo baixo tempo de contato entre a captação e a mistura rápida. Deste modo, a adição de CAP imediatamente a montante da mistura rápida, junto a esta ou a jusante da mistura rápida, tem sido uma opção mais atrativa para muitas ETAs. A maior desvantagem deste tipo de aplicação é que as partículas de CAP podem ser incorporadas aos flocos do hidróxido metálico produzidos durante o processo de coagulação, e conseqüentemente reduzir a eficiência da cinética de transferência dos compostos causadores de gosto e odor para o CAP.

Em função das dúvidas sobre a melhor concepção de sistemas de dosagem e aplicação de CAP para a remoção de compostos orgânicos causadores de gosto e odor em águas de abastecimento, neste artigo são apresentados os resultados experimentais relativos à execução de ensaios de adsorção, combinados com o processo de coagulação, objetivando esclarecer qual é a real influência da coagulação na eficiência de remoção de compostos orgânicos causadores de gosto e odor por intermédio da aplicação de CAP.

\section{OBJETIVOS}

O objetivo desta investigação experimental foi estudar o comportamento do processo de adsorção em carvão ativado em pó combinado com o processo de coagulação em escala de "jartest" na remoção de compostos orgânicos causadores de gosto e odor em águas de abastecimento, tendo sido investigados os seguintes aspectos:

- A interferência do processo de coagulação, mais precisamente do hidróxido metálico precipitado, na eficiência de adsorção de compostos orgânicos causadores de gosto e odor (MIB) em carvão ativado em pó.

- O comportamento cinético do processo de adsorção em carvão ativado em pó na remoção de compostos orgânicos causadores de gosto e odor em águas de abastecimento, quando o CAP é adicionado em conjunto com o coagulante.

- Previsão da capacidade limite do sistema de aplicação de carvão ativado em pó na adsorção de compostos orgânicos causadores de gosto e odor e suas limitações operacionais em função da qualidade da água bruta e dos critérios de qualidade impostos para a água final.

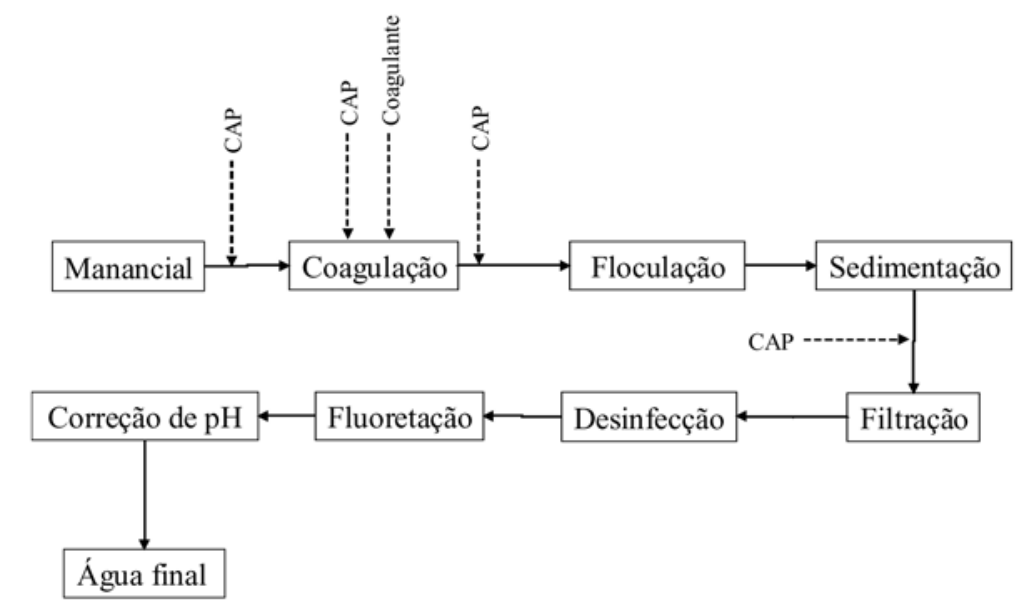

Figura I- Esquema de possíveis pontos de aplicação do CAP em ETAs convencionais 


\section{MATERIAIS E MÉTODOS}

\section{Generalidades}

A pesquisa foi desenvolvida empregando-se a água bruta que abastece ao Sistema Produtor Rio Grande, localizado em São Bernardo do Campo, pertencente e operado pela Companhia de Saneamento Básico do Estado de São Paulo (SABESP) durante o período de junho de 2003 a setembro de 2004 . Os ensaios foram realizados no Laboratório da respectiva ETA, tendo-se executado ensaios cinéticos de adsorção com o propósito de quantificar o grau de interferência da aplicação do coagulante e o meio adsorvedor (CAP). A ETA é do tipo convencional, com vazão de $4,5 \mathrm{~m}^{3} / \mathrm{s}$, responsável pelo abastecimento de cerca de $8 \%$ da população da Região Metropolitana de São Paulo (RMSP), tendo previsão de ampliação para $8,0 \mathrm{~m}^{3} / \mathrm{s}$. As principais características da água bruta estão apresentadas na Tabela 1.

Os problemas de gosto e odor presentes na água bruta que abastece a ETA Rio Grande são, principalmente, oriundos de sub-produtos metabólicos de algas e demais microrganismos, pelo fato do manancial apresentar elevado grau de eutrofização. Dentre os compostos causadores de gosto e odor mais significativos na água bruta, MIB e geosmina tem sido preponderantemente os mais identificados. Pelo fato do composto geosmina ser de mais fácil remoção por processos de adsorção quando comparado com o MIB, este foi o parâmetro de avaliação empregado quando executados os ensaios de adsorção.

Uma vez que, durante o período de investigação experimental, a água bruta utilizada nos ensaios experimentais poderia não conter o composto MIB, este foi adicionado a mesma de modo que a sua concentração situasse entre 200 a 400 ng/L, valores estes representativos da água bruta proveniente do manancial quando dos episódios de gosto e odor mais significativos. Portanto, para cada ensaio executado era adicionada alíquota de padrão de MIB (Wako Chemicals), a fim de conferir a água bruta à concentração desejada.

Nos ensaios experimentais empregou-se sulfato férrico $\mathrm{Fe}_{2}\left(\mathrm{SO}_{4}\right)_{3}$ como coagulante, pelo fato deste ser utilizado na ETA Rio Grande, tendo-se variado a sua dosagem em alguns ensaios específicos a fim de possibilitar a avaliação da provável interferência do hidróxido metálico precipitado no processo de adsorção.

Tabela I - Características da água bruta do sistema produtor Rio Grande (Represa Billings). Valores médios e desvio padrão

(DP) - Período de amostragem de Janeiro de 2003 a Julho de 2004

\begin{tabular}{ccc}
\hline Parâmetro & Unidade & Valores médios $\pm \mathrm{DP}$ \\
\hline $\mathrm{pH}$ & - & $7,34 \pm 0,35$ \\
Temperatura & ${ }^{\circ} \mathrm{C}$ & $22,1 \pm 2,6$ \\
Turbidez & $\mathrm{UT}$ & $6,2 \pm 3,4$ \\
Cor & $\mathrm{UC}$ & $38,3 \pm 8,9$ \\
Condutividade & $\mathrm{mmho} / \mathrm{cm}$ & $301 \pm 45$ \\
COT & $\mathrm{mg} / \mathrm{L}$ & $8,1 \pm 1,5$ \\
DQO & $\mathrm{mg} / \mathrm{L}$ & $17,6 \pm 3,3$ \\
OD & $\mathrm{mg} / \mathrm{L}$ & $4,6 \pm 1,1$ \\
Cloretos & $\mathrm{mg} / \mathrm{L} \mathrm{Cl}$ & $66,6 \pm 11,1$ \\
Manganês solúvel & $\mathrm{mg} / \mathrm{L}$ & $0,17 \pm 0,05$ \\
Ferro & $\mathrm{mg} / \mathrm{L}$ & $0,43 \pm 0,24$ \\
Cobre & $\mathrm{mg} / \mathrm{L}$ & $0,06 \pm 0,07$ \\
Fósforo total & $\mathrm{mg} / \mathrm{L}$ & $0,034 \pm 0,002$ \\
Nitrogênio amoniacal & $\mathrm{mg} / \mathrm{L}$ & $0,36 \pm 0,16$ \\
Nitrato & $\mathrm{mg} / \mathrm{L}$ & $0,11 \pm 0,05$ \\
\hline
\end{tabular}

Fonte: Marchetto, M. (2004)

Em relação ao CAP empregado na investigação experimental, foram avaliados dois tipos distintos de carvão, um de origem vegetal de fabricação nacional (Brascarbo - Número de iodo: $600 \mathrm{mg} / \mathrm{g}$ ), sendo este atualmente empregado na ETA Rio Grande, e outro de origem mineral (CALGON - WPH Número de iodo: $870 \mathrm{mg} / \mathrm{g}$ ).

A Tabela 2 apresenta um quadro resumo dos ensaios de adsorção realizados. Ambos os CAPs serão doravante denominados de CAP-V (CAP de origem vegetal) e CAP-M (CAP de origem mineral).

\section{Procedimentos experimentais}

O procedimento experimental consistiu de ensaios em equipamento de "jartest", com uma série de seis jarros com capacidade de 2 litros cada, tendo-se variado as dosagens e tempos de contato de CAP, as dosagens de coagulante e pontos de aplicação. Um jarro foi usado como controle ( $0 \mathrm{mg} / \mathrm{L}$ de CAP), sendo que os demais simularam o ponto de aplicação de CAP para diferentes tempos de contato.

Os ensaios experimentais foram executados da seguinte forma: inicialmente, a água bruta era disposta em uma caixa de cimento amianto de capacidade igual a 50 litros. Procedia-se então a introdução de MIB na água bruta com o auxilio de micro-seringa, a fim de obter concentração inicial do adsorvato na faixa de 200 a $400 \mathrm{ng} / \mathrm{L}$. A homogeneização da água bruta e do adsorvato era efetuada com o auxilio de um agitador mecânico de alta capacidade com rotação igual a $300 \mathrm{rpm}$, para que os sólidos em suspensão presentes na água bruta permanecessem na fase líquida e fosse evitada a volatilização de MIB para a fase gasosa.

Após 10 minutos de homogeneização coletava-se amostras de água bruta em duplicata para a determinação da concentração de MIB, sendo posteriormente transferidos dois litros da mesma para cada jarros do equipamento de "jar-test". A solução do coagulante era preparada no início de cada ensaio com concentração de $5 \mathrm{~g} \mathrm{Fe}_{2}\left(\mathrm{SO}_{4}\right)_{3} / \mathrm{l}$.

A rotação do sistema de agitação para mistura rápida foi mantida a um valor em torno de $200 \mathrm{rpm}$, e a aplicação da suspensão de CAP realizada simultaneamente em todos os jarros.

Após 15 minutos da adição de CAP (simulação de aplicação de CAP na captação) efetuava-se o ajuste do $\mathrm{pH}$ de coagulação (quando necessário) e após de- 
Tabela 2 - Ensaios realizados com água bruta do Rio Grande - (Captação da ETA Rio Grande) com adição de padrão de MIB

\begin{tabular}{|c|c|c|c|c|}
\hline \multirow[t]{2}{*}{ Ensaios } & \multirow[t]{2}{*}{ CAP } & \multirow[t]{2}{*}{ Aplicação do CAP } & \multicolumn{2}{|c|}{ Dosagem $(\mathrm{mg} / \mathrm{L})$} \\
\hline & & & CAP & Coagulante $\mathrm{Fe}_{2}\left(\mathrm{SO}_{4}\right)_{3}$ \\
\hline 01 & $\begin{array}{l}\text { Calgon e } \\
\text { Brascarbo }\end{array}$ & 20 min antes da coagulação & $0 ; 5 ; 10 ; 20 ; 30$ e 40 & 25 \\
\hline 02 & $\begin{array}{l}\text { Calgon } \\
\text { Brascarbo }\end{array}$ & 20 min antes da coagulação & $0 ; 5 ; 10 ; 20 ; 30$ e 40 & 25 \\
\hline 03 & Brascarbo & $\begin{array}{l}20 \text { min antes da coagulação } \\
30 \text { s após coagulação }\end{array}$ & $0 ; 5 ; 10 ; 20 ; 30$ e 40 & 25 \\
\hline 04 & Brascarbo & $\begin{array}{c}20 \text { min antes da coagulação } \\
30 \text { s após coagulação } \\
\text { Somente CAP }\end{array}$ & $0 ; 5 ; 10 ; 20 ; 30$ e 40 & 25 \\
\hline 05 & Brascarbo & $\begin{array}{c}1 \text { min antes da coagulação } \\
1 \text { min após a coagulação } \\
\text { Somente CAP }\end{array}$ & $0 ; 5 ; 10 ; 20 ; 30$ e 40 & 25 \\
\hline 06 & Brascarbo & $\begin{array}{c}1 \text { min antes da coagulação } \\
1 \text { min após a coagulação } \\
\text { Somente CAP }\end{array}$ & $0 ; 5 ; 10 ; 20 ; 30$ e 40 & 25 \\
\hline 07 & $\begin{array}{l}\text { Calgon e } \\
\text { Brascarbo }\end{array}$ & $\begin{array}{c}1 \text { min antes da coagulação } \\
1 \text { min após a coagulação } \\
\text { Somente CAP }\end{array}$ & 40 & 25 \\
\hline 08 & Brascarbo & $\begin{array}{c}\text { Somente CAP } \\
30 \text { s após coagulação }\end{array}$ & 20 & $0 ; 5 ; 10 ; 15 ; 20$ e 30 \\
\hline 09 & Brascarbo & $\begin{array}{c}\text { Somente CAP } \\
1 \mathrm{~min} \text { antes da coagulação }\end{array}$ & 20 & $0 ; 5 ; 10 ; 20$ e 30 \\
\hline 10 & Brascarbo & $\begin{array}{c}\text { Somente CAP } \\
1 \mathrm{~min} \text { antes da coagulação }\end{array}$ & 40 & $0 ; 5 ; 10 ; 20$ e 30 \\
\hline 11 & Brascarbo & $\begin{array}{c}\text { Somente CAP } \\
1 \mathrm{~min} \text { antes da coagulação }\end{array}$ & 20 & $0 ; 5 ; 10 ; 20$ e 30 \\
\hline
\end{tabular}

Obs: O Ensaio 2 foi realizado com pH de coagulação igual a 8,5; os demais ensaios foram realizados com pH de coagulação próximos a 6,5 .

corrido o tempo de mistura do CAP e do alcalinizante ( 15 segundos) era efetuada a adição simultânea do coagulante.

Imediatamente após a mistura rápida, reduzia-se a rotação do sistema de agitação de modo a permitir a simulação do processo de floculação, tendo os mesmos gradientes de velocidade iguais a $70 \mathrm{~s}^{-1}$, $50 \mathrm{~s}^{-1}$ e $30 \mathrm{~s}^{-1}$ e tempo total de $30 \mathrm{minu}$ tos. Decorrido este tempo, desligava-se o sistema de agitação e aguardava-se a sedimentação dos flocos por 5 minutos.

Com o objetivo de permitir diferentes tempos de contato do CAP com a fase líquida, as coletas de água floculada foram efetuadas nos tempos de contato iguais a $5,10,15,20$ e 30 minutos. A separação das partículas coloidais e em suspensão na fase líquida foi efetuada mediante filtração em membrana filtrante com $0,45 \mu \mathrm{m}$ de diâmetro médio dos poros. O filtrado proveniente de cada amos- tra coletada simultaneamente em todos os jarros em um tempo pré-definido foi disposto em duplicata em frascos de cromatografia para a análise da concentração de MIB na fase líquida.

Os ensaios preliminares foram realizados com duas marcas comerciais de CAP e tendo-se adotados os seguintes parâmetros: concentrações de CAP de $0,5,10,20,30,40$ e $50 \mathrm{mg} / \mathrm{L}$ e dosagem fixa do coagulante sulfato férrico $\mathrm{Fe}_{2}\left(\mathrm{SO}_{4}\right)_{3}$ de $25 \mathrm{mg} / \mathrm{L}$ com (pH em torno de 6,5 e 8,5); tempo de floculação de 15 minutos associado a gradientes médios de velocidades decrescentes com valores de $70 \mathrm{~s}^{-1}, 50 \mathrm{~s}^{-1}$ e $30 \mathrm{~s}^{-1}$, com tempo de 5 minutos para cada gradiente de velocidade.

Os ensaios subseqüentes foram conduzidos com CAP-V por ter este apresentado resultados experimentais ligeiramente superiores ao CAP-M. A verifica- ção da significância do ponto de aplicação de CAP junto a ETA foi avaliada tendo-se dosado o mesmo 20 minutos antes da coagulação, 30 segundos e 1 minuto antes da adição do coagulante e 1 minuto após a adição do coagulante.

Com o objetivo de estudar a cinética do processo de adsorção de MIB pelo CAP e a influência do hidróxido metálico precipitado durante o processo de coagulação, foram executados ensaios experimentais com diferentes tempos de floculação $(5,10,15,20,25$ e 30 minutos), tendo-se mantido constantes a dosagem de CAP (20 mg/L e $40 \mathrm{mg} / \mathrm{L})$ e variado as dosagens de $\mathrm{Fe}_{2}\left(\mathrm{SO}_{4}\right)_{3}(0,5$, $10,15,20,30 \mathrm{mg} / \mathrm{L})$.

Todas as determinaçōes referidas foram realizadas utilizando-se os equipamentos localizados no laboratório da ETA Rio Grande. As análises de MIB foram efetuadas com cromatografia gasosa asso- 
ciado a espectrofotômetro de massa pelo laboratório de Química Orgânica da Companhia de Saneamento Básico do Estado de São Paulo (TCCL-SABESP) por CG-MS-PAT, seguindo as recomendaçōes da APHA (1998).

\section{APRESENTACÃO E ANALISE DOS RESULTADOS EXPERIMENTAIS}

\section{Seleção do carvão ativado em pó}

Os resultados experimentais relativos aos ensaios 1 e 2 (Tabela 2) estão apresentados nas Figuras 2 e 3, respectivamente. Estes foram conduzidos tendo-se por objetivo avaliar a eficiência de diferentes marcas comerciais de CAP no processo de adsorção, foi adotado um tempo total de contato do CAP com a fase líquida de 35 minutos, simulandose aplicação na captação de água bruta com 20 minutos de tempo de contato antes da coagulação e 15 minutos após a coagulação.

Observa-se que, dentre os CAPs testados (CAP-V e CAP-M), o CAP-V proporcionou resultados iguais ou superiores em relação à remoção de MIB da fase líquida. A eficiência de remoção situou-se na faixa de $60 \%$ a $70 \%$ para o CAP-V para dosagens aplicadas da ordem de $20 \mathrm{mg} / \mathrm{L}$.

Para o CAP-V, os resultados dos ensaios realizados com $\mathrm{pH}$ de coagulação próximo a 6,5 e apresentado na Figura 2 foram bastante similares quando comparado com os ensaios conduzidos com pH de coagulação em torno de 8,5 (Figura 3), não se tendo observado nenhuma diferença significativa entre ambos. No entanto, para o CAP-M, observa-se que os maiores valores de eficiência de remoção de MIB foram obtidos quando o processo de coagulação foi conduzido na faixa de $\mathrm{pH}$ próximo de 6,5. Esta diferença de comportamento no processo de adsorção de MIB em função da natureza do material adsorvente pode estar relacionada às suas propriedades físicoquímicas que, são ditadas pela matéria prima empregada em sua fabricação e processo de ativação (tempo de contato, temperatura de ativação, etc...).

Deste modo, evidencia-se que o $\mathrm{pH}$ da fase líquida não influenciou na eficiência do processo de adsorção de MIB para o CAP-V e tal fato é de grande rele-

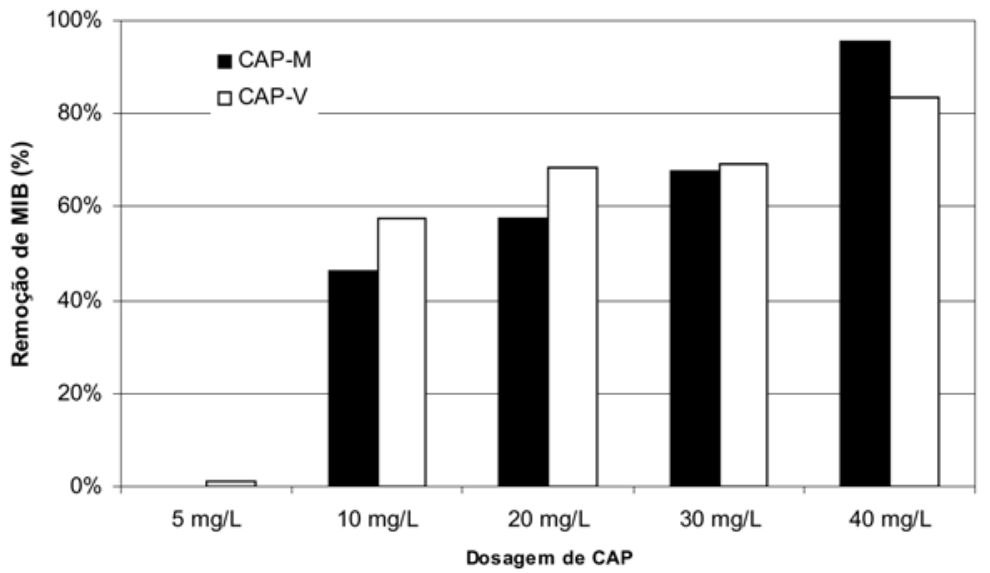

Figura 2 - Aplicação de CAP 20 minutos antes da mistura rápida. Dosagem fixa de coagulante igual a 25 mg/L e pH de coagulação igual a 6,3. Tempo de contato total igual a 35 minutos

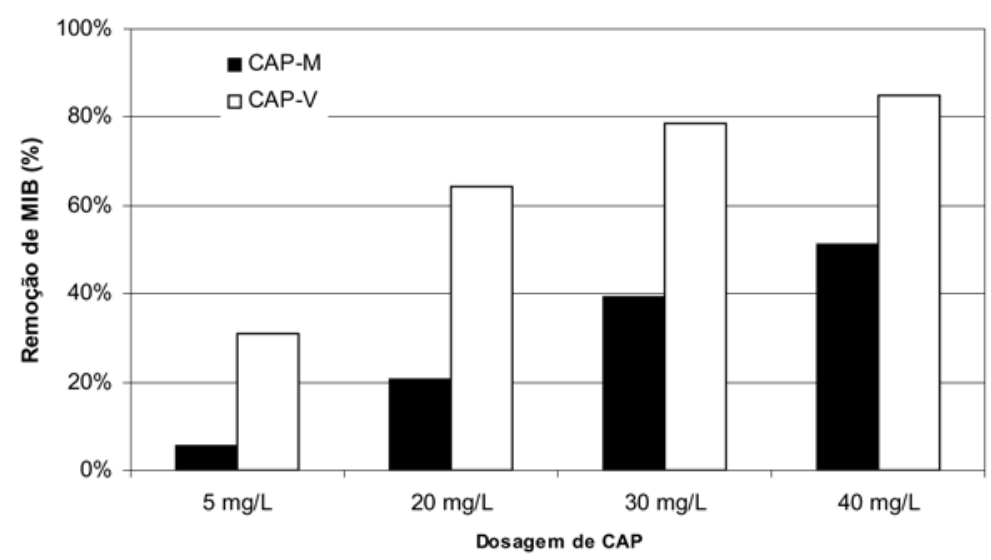

Figura 3 - Aplicação de CAP 20 minutos antes da mistura rápida. Dosagem fixa de coagulante igual a $25 \mathrm{mg} / \mathrm{L}$ e pH de coagulação igual a 8,5. Tempo de contato total igual a 35 minutos

vância para a ETA Rio Grande, uma vez que o $\mathrm{pH}$ de coagulação é ajustado ao longo do ano em função da qualidade da água bruta (presença de ferro e manganês o que requer a prática de pré-oxidação e elevação do pH de coagulação) e, deste modo, espera-se que não haja interferência na remoção de compostos orgânicos causadores de gosto e odor em águas de abastecimento.

Uma vez que os carvões ativados de origem vegetal apresentam maior disponibilidade e menor preço no mercado nacional do que quando comparado com os carvôes ativados de origem mineral, geralmente importados, a sua adoção é uma grande vantagem no tocante ao seu uso no tratamento de águas de abastecimento (Ferreira Filho, 2003).

Para o CAP-M e aplicado com dosagens em torno de $20 \mathrm{mg} / \mathrm{L}$ (Figura 2) obteve-se aproximadamente $60 \%$ de remoção de MIB e, para dosagens de CAP entre $20 \mathrm{mg} / \mathrm{L}$ e $30 \mathrm{mg} / \mathrm{L}$, foram obtidas remoções próximas a $80 \% \mathrm{com}$ concentraçôes finais de MIB superiores a $30 \mathrm{ng} / \mathrm{L}$. Os melhores resultados foram alcançados com dosagens de CAP da ordem de $40 \mathrm{mg} / \mathrm{L}$ em que foram obtidas concentraçôes de MIB entre $11 \mathrm{e}$ $20 \mathrm{ng} / \mathrm{L}$.

De um modo geral, dois aspectos podem ser ressaltados observando-se os resultados apresentados nas Figuras 2 e 3, a saber: o primeiro está diretamente relacionado com as dosagens de CAP aplicadas na água bruta que permitam uma eficiência razoável de remoção de MIB. Para dosagens iguais ou inferiores a $10 \mathrm{mg} / \mathrm{L}$, a eficiência do processo de adsorção em CAP é muito reduzida, o que torna sua aplicação desnecessária. O segundo aspecto a ser ressaltado está relacionado com a importância da correta seleção do CAP a ser em- 
pregado em uma ETA a fim de permitir a solução de problemas específicos.

Conforme já dito anteriormente, os CAPs disponíveis no mercado podem ser produzidos a partir de diferentes tipos de matérias primas e obtidos por diferentes processos de produção. Devido à especificidade dos compostos a serem removidos por processos de adsorção em carvão ativado, é de se esperar que diferentes CAPs apresentem também diferentes comportamentos em relação à remoção de compostos orgânicos o que irá exigir a condução de ensaios experimentais a fim de ser possível avaliar qual o mais adequado. Para o caso específico em questão, o fato do CAP-V ter apresentado melhores resultados quando comparado com o CAP-M é de grande relevância, uma vez que aquele é de origem vegetal e produzido no Território Nacional, ao passo que o CAP-M é de origem mineral e importado, com custo superior.

Deste modo, em função dos resultados obtidos, definiu-se que os ensaios subseqüentes seriam realizados com CAP-V, por ter este apresentado eficiência de remoção de MIB maior quando comparado com o CAP-M e por ser o mesmo utilizado pela ETA Rio Grande em escala real. Os pontos de adição de CAP foram alterados, com simulação de diferentes cenários de aplicação; na captação, minutos antes e após a coagulação. As simulações foram realizadas para verificar a interferência ou competição do hidróxido férrico precipitado durante o processo de coagulação com o CAP.

\section{IMPORTÂNCIA DO TEMPO DE CONTATO NO PROCESSO DE ADSORÇÃO}

Os resultados experimentais relativos aos Ensaios 3 e 4 (Tabela 2) estão apresentados nas Figuras 4 e 5, respectivamente. Estes foram conduzidos tendo-se por objetivo avaliar a significância do tempo de contato do CAP com a fase líquida no processo de adsorção, e também o estudo da aplicação do CAP junto à captação (tempo de contato com a fase líquida total de 35 minutos) e imediatamente após a coagulação (tempo de contato com a fase líquida total de 15 minutos).

Observando-se os resultados experimentais apresentados na Figura 4 verifica-se que para um tempo de contato de CAP de 35 minutos, correspondente a aplicação de CAP junto à captação, os resultados de remoção de MIB foram li- geiramente superiores quando comparado com os ensaios experimentais que simularam a aplicação de CAP 30 segundos após a coagulação.

Deste modo, em face dos resultados experimentais, torna-se recomendável que, sempre que possível, a aplicação de CAP para fins de remoção de compostos causadores de gosto e odor seja sempre efetuada de modo a ser maximizado o tempo de contato com a fase líquida.

No entanto, deve ser ressaltado que nem sempre a concepção do sistema produtor permite que a aplicação do CAP possa ser efetuada junto à captação, seja devido a proximidade desta com a ETA ou em função da dificuldade de logística no tocante a operação do sistema de aplicação de CAP.

Um aspecto interessante a ser observado é que, ainda que se tenha obtido uma maior eficiência de remoção de MIB com aplicação de CAP junto à captação quando comparada com a sua aplicação junto a mistura rápida, esta pode ser considerada reduzida, da ordem de não mais do que $20 \%$. Isto significa que para a ETA que não possua condições de aplicação de CAP junto à captação, a sua dosagem não fica inviabilizada, uma vez que a mesma pode ser efetuada junto à mistura rápida e o tempo de contato entre o CAP e os compostos orgânicos causadores de gosto e odor será o existente no sistema de floculação.

A similaridade dos resultados de eficiência de remoção de MIB para ambas as situações de aplicação de CAP na água bruta e na mistura rápida (Figura 4 e 5) indica a ineficácia do processo de coagulação na remoção de compostos orgânicos naturais (CONs) que porventura possam interferir no processo de adsorção, dado que o processo de coagulação remove preferencialmente moléculas de CONs de alto peso molecular, não removendo as fraçôes que apresentam baixo peso molecular e que possuem maior capacidade de competirem

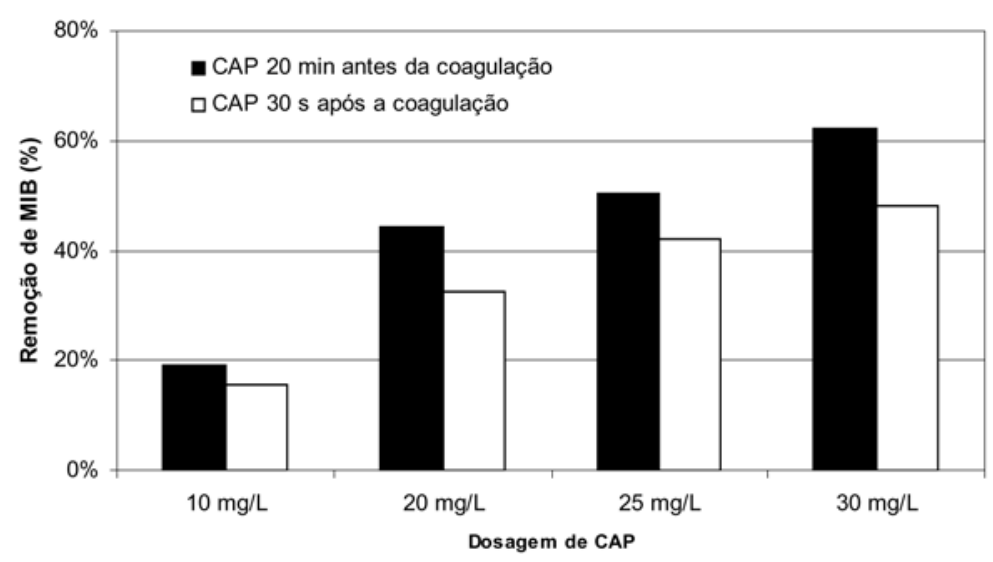

Figura 4 - Aplicação de CAP-V. Dosagem fixa de coagulante igual a $25 \mathrm{mg} / \mathrm{L}$ e pH de coagulação igual a 6,3

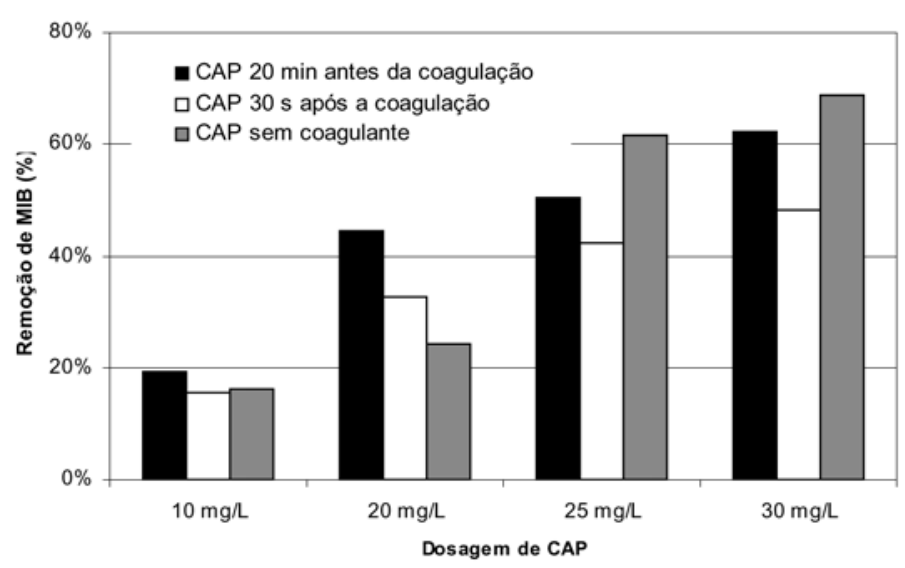

Figura 5 - Aplicação de CAP-V. Dosagem fixa de coagulante igual a $25 \mathrm{mg} / \mathrm{L}$ e pH de coagulação igual a 6,3 
pelos mesmos sítios de adsorção do CAP responsáveis pela remoção de MIB.

É importante ressaltar que este comportamento do processo de coagulação e sua interferência no processo de adsorção é específica para a água bruta empregada nesta investigação experimental, não podendo ser generalizada, dada a diversidade de composição e origem dos CONs presentes em águas naturais.

Como era de se esperar, verifica-se que ocorreu um aumento na remoção de MIB com o aumento da dosagem de CAP aplicado na fase líquida, o que reforça a importância da sua dosagem a fim de que seja possível atingir valores de eficiência satisfatórias de remoção de MIB. Deste modo, tão ou mais importante que o tempo de contato entre o CAP e a fase líquida, faz-se de grande significância a correta escolha da dosagem de CAP aplicada na fase líquida.

\section{INTERFRÊNCIA DO PROCESSO DE COAGULAÇÁO NO PROCESSO'DE ADSORÇÃO}

A aplicação do CAP junto à mistura rápida pode ser efetuada antes, depois ou juntamente com o coagulante. Em face das dúvidas existentes com respeito a possível incorporação das partículas de CAP no hidróxido metálico precipitado oriundo da adição do coagulante e sua interferência no processo de adsorção, foram conduzidos ensaios experimentais que simularam ambos os cenários de aplicação de CAP junto à mistura rápida (Ensaios 5 e 6-Tabela 2). Os seus resultados experimentais estão apresentados nas Figuras 6 e 7, respectivamente, tendo-se admitido a aplicação de CAP 1 min antes da coagulação, 1 min após a coagulação e somente CAP.

Observando-se os resultados experimentais apresentados nas Figuras 6 e 7 , independentemente do ponto de aplicação de CAP, reforça-se a importância da sua dosagem no tocante à remoção de MIB. Dosagens de CAP iguais a $10 \mathrm{mg} / \mathrm{L}$ produziram valores de remoção de MIB bastante insatisfatórios, não superiores a $20 \%$, o que significa que dosagens iguais ou inferiores a este valor podem ser consideradas inadequadas no tocante a remoção de MIB. As maiores eficiências de remoção foram atingidas quando as dosagens de CAP foram iguais ou superiores a $20 \mathrm{mg} / \mathrm{L}$, aumentando gradati-

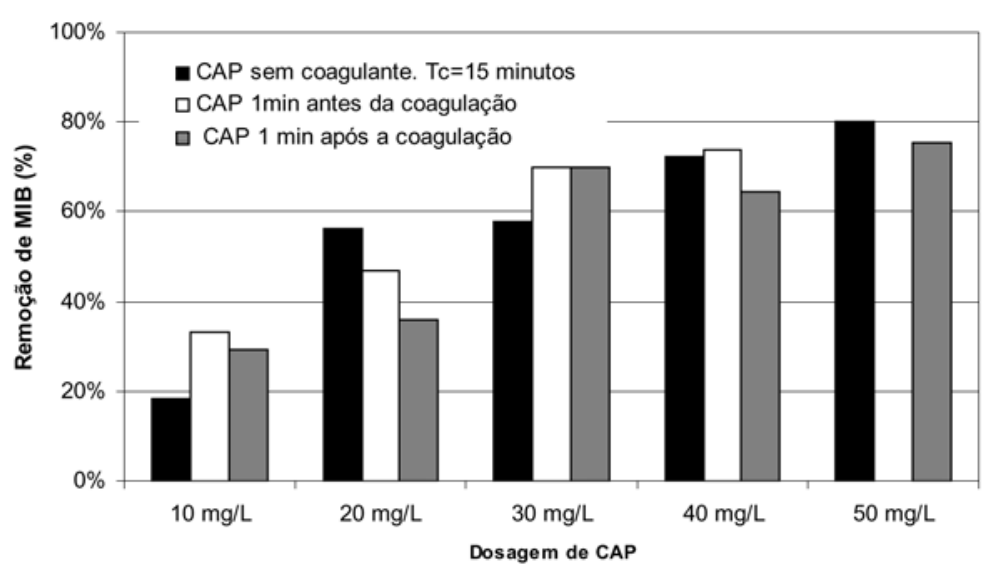

Figura 6 - Aplicação de CAP-V. Dosagem fixa de coagulante igual a 25 mg/L e pH de coagulação igual a 6,3

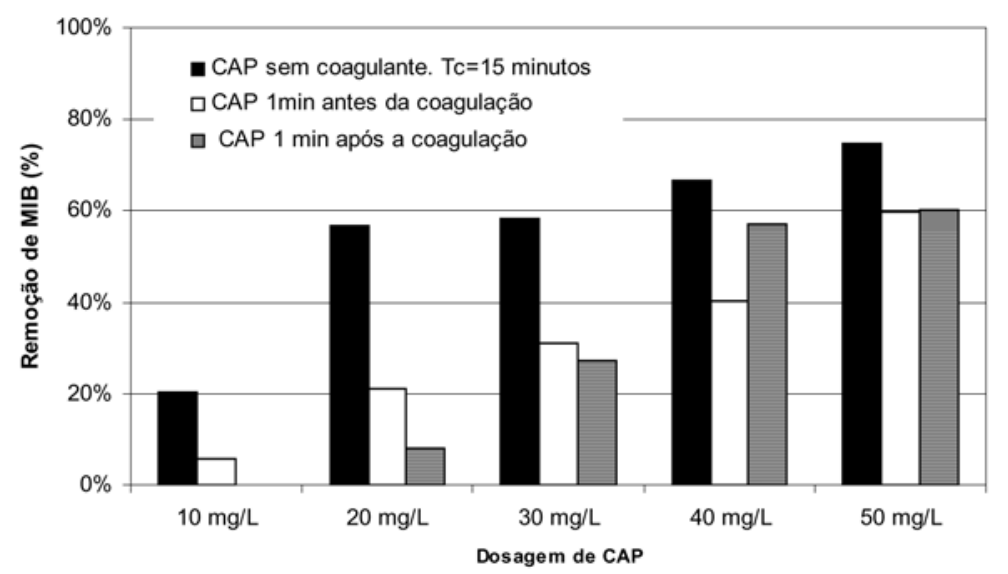

Figura 7 - Aplicação de CAP-V. Dosagem fixa de coagulante igual a 25 mg/L e pH de coagulação igual a 6,3

vamente com o respectivo aumento da dosagem de CAP.

Comparando-se os resultados de remoção de MIB para as mesmas dosagens de coagulante aplicadas, independentemente do seu ponto de aplicação, não foram observadas diferenças significativas em seus valores, o que indica que o ponto de aplicação de CAP, seja ele antes ou depois da aplicação do coagulante, possui pouca importância na eficiência do processo de adsorção.

No entanto, um dos aspectos importantes a serem considerados quando da aplicação do CAP junto à mistura rápida está relacionada não diretamente com a eficiência do processo de adsorção e sim com a qualidade da água decantada.

Uma vez tendo sido o CAP dosado anteriormente ao coagulante, as suas partículas são, conseqüentemente, incorpo- rados nos flocos de hidróxido metálico formado e, desta forma, removidos por processos de sedimentação. No entanto, caso o CAP seja aplicado após a adição do coagulante, a probabilidade de que as suas partículas sejam incorporadas nos flocos de hidróxido metálico precipitado passa a ser menor, esperando-se, portanto, uma piora na qualidade da água decantada, o que irá refletir-se no comportamento do sistema de filtração.

Dado que não foram observadas diferenças significativas com respeito à aplicação do CAP anteriormente ou após a adição do coagulante, com o objetivo de preservar a qualidade da água decantada, recomenda-se que, sempre que possível, o CAP seja adicionado antes do coagulante ou, no máximo, juntamente com este. 


\section{INTERFERÊNCIA DO PROCESSO DE COAGULACÃO NA CINETICA DO PROCESSO DE ADSORÇÃO}

Com o objetivo de avaliar a cinética do processo de adsorção e a sua possível interferência pelos flocos de hidróxido férrico metálico precipitado, foram conduzidos ensaios cinéticos de adsorção tendo-se mantido fixa a dosagem de CAP e variado a dosagem de coagulante metálico (Ensaios 8, 9, 10 e 11 -Tabela 2). Os resultados experimentais relativos aos Ensaios 8, 9 e 10 estão apresentados nas Figuras 8, 9 e 10, respectivamente.

Observando-se os resultados experimentais apresentados na Figura 8, podese constatar que, para a dosagem de CAP fixa em $20 \mathrm{mg} / \mathrm{L}$, independentemente da dosagem de coagulante aplicada, não se observou nenhuma diferença significativa entre os valores de remoção de MIB na fase líquida.

Assim sendo, tanto para uma dosagem de 5,0 mg Fe ${ }_{2}\left(\mathrm{SO}_{4}\right)_{3} / \mathrm{L}$ como $30,0 \mathrm{mg} \mathrm{Fe}_{2}\left(\mathrm{SO}_{4}\right)_{3} / \mathrm{L}$, a eficiência de remoção de MIB apresentou-se ser indiferente, o que indica que a eventual presença do hidróxido metálico precipitado no entorno das partículas de CAP não apresentou resistência significativa no processo de transferência de massa.

Do ponto de vista físico, a cinética do processo de adsorção pode ser vista como um conjunto de processos de transferência de massa em série que representam o transporte do adsorvato da fase líquida até no interior do adsorvente. Deste modo, para que o processo de adsorção seja factível, o adsorvato tem que atingir a camada externa do material adsorvente (transferência externa de massa) e posteriormente difundir-se internamente ao longo de seus poros internos (transferência interna de massa por difusão superficial e porosa).

Uma vez tendo-se observado que os flocos de hidróxido férrico precipitados não causaram nenhuma interferência significativa no processo de adsorção de MIB pelo CAP, pode-se postular que a cinética de adsorção de MIB foi limitada por processos de transferência interna de massa do adsorvato no interior dos poros das partículas de CAP.

Outro aspecto interessante a ser observado é que, mantida a dosagem de coagulante e CAP constante, com o aumento do tempo de contato entre este e a fase líquida, observou-se um ligeiro au-

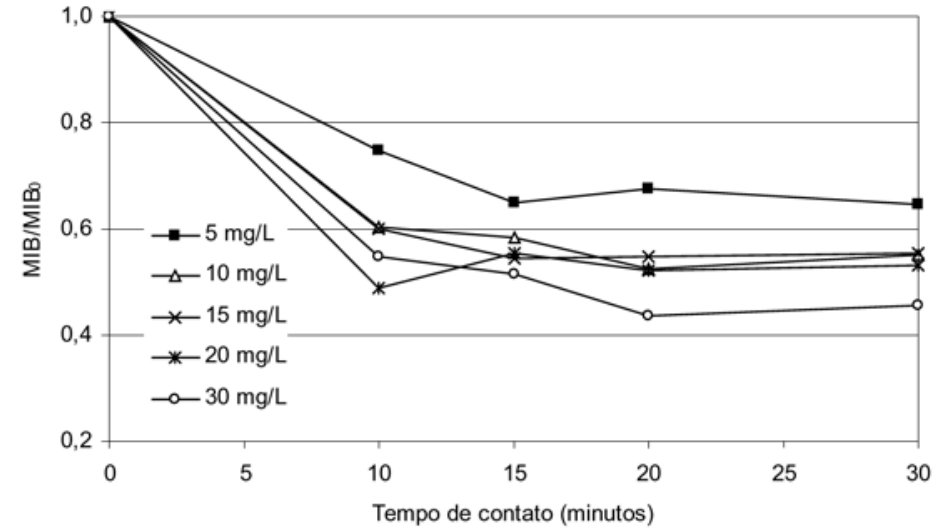

Figura 8 - Aplicação de CAP 30 segundos após a mistura rápida. Dosagem de CAP igual a 20 mg/L e diferentes dosagens de coagulante. $\mathrm{pH}$ de coagulação igual a 6,3

mento na eficiência de remoção de MIB, no entanto, este acréscimo foi bastante reduzido indicando que tempos de contato iguais ou superiores à 10 minutos foram razoáveis a fim de que fosse possível atingir o equilíbrio entre o MIB e o material adsorvente. Resultados semelhantes também foram obtidos por Ferreira Filho (2003), tendo-se estudado a adsorção de MIB para diferentes marcas comerciais de CAP, tanto de origem mineral como vegetal.

As Figuras 9 e 10 apresentam os resultados experimentais relativos aos ensaios cinéticos de adsorção conduzidos com dosagens de CAP iguais a $20 \mathrm{mg} / \mathrm{L} \mathrm{e}$ $40 \mathrm{mg} / \mathrm{L}$, respectivamente.

Mais uma vez, pode-se observar que, tendo-se mantido fixo o tempo de contato entre o CAP e a fase líquida, independentemente da dosagem de coagulante, os valores de remoção de MIB apresentaram valores bastante semelhantes entre si, o que reforça a hipótese de que, mesmo estando as partículas de CAP incorporadas pelos flocos de hidróxido metálico precipitado, a resistência limitante no processo de transferência de massa do MIB para os sítios de adsorção localizados no interior do material adsorvedor não é a externa e sim a interna ao longo da superfície dos poros do CAP.

Comparando-se as Figuras 9 e 10, pode-se observar que as maiores eficiências de remoção de MIB foram obtidas para os ensaios cinéticos conduzidos com dosagens de CAP iguais a $40 \mathrm{mg} / \mathrm{L}$, o que reforça a importância da sua dosagem na eficiência de remoção de compostos orgânicos causadores de gosto e odor em águas de abastecimento.

Logo, na grande maioria dos casos em que é efetuada a aplicação de CAP em estações de tratamento de água para o controle de gosto e odor, caso estes tenham por origem os sub-produtos metabólicos de algas e demais microrganismos, dosagens inferiores a $20 \mathrm{mg} / \mathrm{L}$ podem não ser suficientes a fim de que seja possível atingir valores de remoção de permitam um controle efetivo do problema em questão. Recomenda-se, portanto, que a correta definição das dosagens adequadas de CAP a serem aplicadas em uma específica água bruta e estação de tratamento de água seja determinada em função de ensaios experimentais específicos, que levem em consideração as peculiaridades do sistema produtos.

Assim sendo, tendo por base os resultados experimentais obtidos, pode-se concluir que, sob as condições testadas na presente pesquisa, a interferência do hidróxido metálico precipitado oriundo do processo de coagulação no processo de adsorção, se houver, não é significativa a tal ponto de inviabilizar a aplicação de CAP junto à mistura rápida.

Recomenda-se que, para as dosagens de CAP empregadas nesta investigação experimental, que este seja aplicado anteriormente ao coagulante ou, no máximo, juntamente com este, a fim de que seja possível preservar a qualidade da água decantada, permitindo a incorporação das partículas de CAP nos flocos formados e sua posterior remoção por sedimentação gravitacional.

\section{CONCLUSÕES E RECOMENDAÇŌES FINAIS}

Com base no exposto e em função dos resultados experimentais obtidos, pode-se concluir que: 


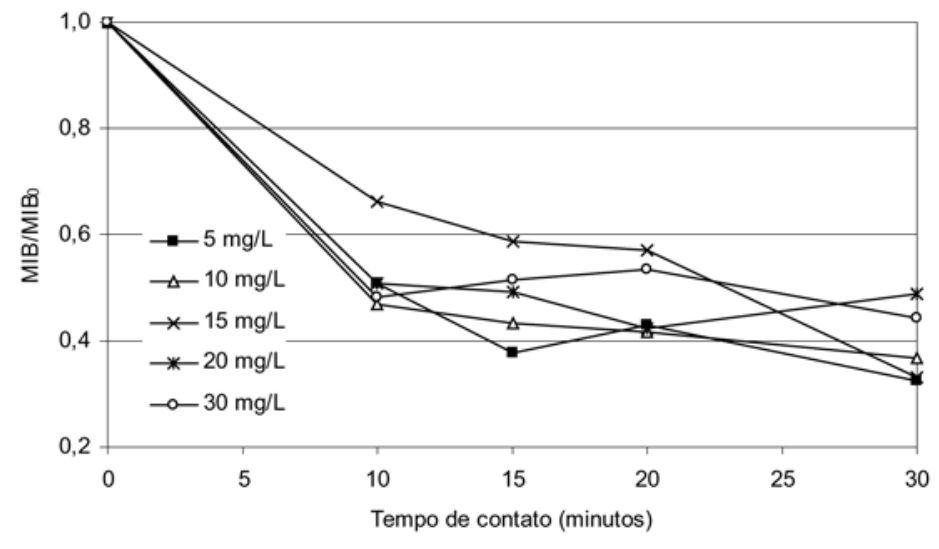

Figura 9 - Aplicação de CAP I minuto antes da mistura rápida. Dosagem

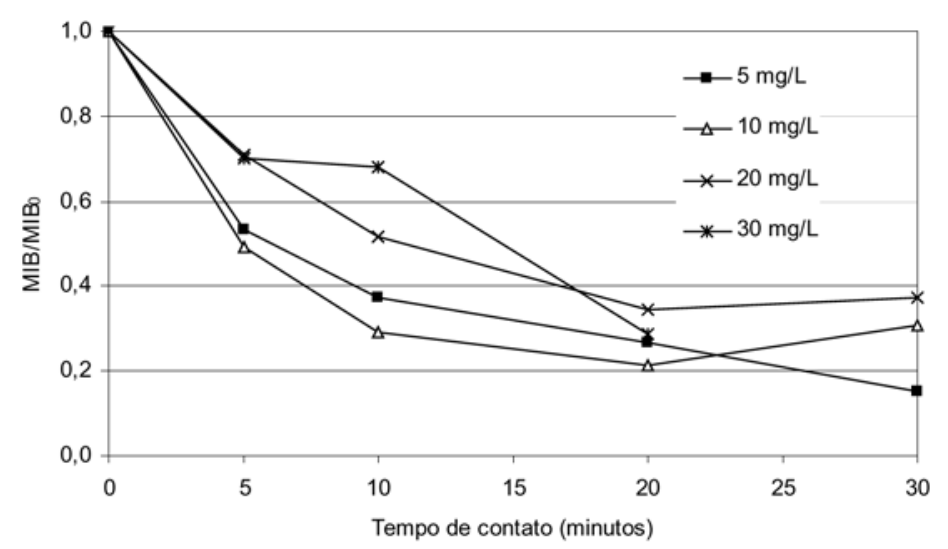

Figura 10 - Aplicação de CAP I minuto antes da mistura rápida. Dosagem
de CAP igual a $40 \mathrm{mg} / \mathrm{L}$ e diferentes dosagens de coagulante. $\mathrm{pH}$ de
coagulação igual a 6,3

- Embora ambos os CAP utilizados na investigação experimental tenham fornecido resultados satisfatórios de remoção de MIB na fase líquida, o CAP-V, de origem vegetal, forneceu melhores resultados quando comparado com o CAP$\mathrm{M}$, de origem mineral.

- Com o objetivo de otimizar a aplicação de CAP visando à remoção de compostos orgânicos causadores de gosto e odor em águas de abastecimento torna-se recomendável que, sempre que possível, a sua aplicação seja sempre efetuada de modo a ser maximizado o tempo de contato com a fase líquida.

- Com o aumento da dosagem de CAP verificou-se um aumento na remoção de MIB na fase líquida, o que reforça a importância da correta seleção da sua dosagem a fim de que seja possível atingir valores de eficiência satisfatória de remoção. Deste modo, tão ou mais importante diçōes testadas, o ponto de aplicação de CAP seja ele antes ou depois da aplicação do coagulante, possui pouca importância na eficiência do processo de adsorção.

- Assim sendo, para as dosagens de coagulante e CAP empregadas, a interferência do hidróxido metálico precipitado oriundo do processo de coagulação no processo de adsorção, se houver, não é significativa a tal ponto de inviabilizar a aplicação de CAP junto à mistura rápida.

- Dado que não foram observadas diferenças significativas com respeito à aplicação do CAP anteriormente ou após a adição do coagulante, com o objetivo de preservar a qualidade da água decantada, recomenda-se que, sempre que possível, o CAP seja adicionado antes do coagulante ou, no máximo, juntamente com este.

\section{AGRADECIMENTOS}

ÀFAPESP (Fundação de Amparo a Pesquisa do Estado de São Paulo) pelo suporte financeiro concedido (Bolsa de Pós-Doutoramento 2003/00536-6).

À SABESP (Companhia de Saneamento Básico do Estado de São Paulo), por permitir a realização da pesquisa nas dependências do Laboratório da Estação de Tratamento de Água do Rio Grande.

À equipe técnica do laboratório de Química Orgânica (TCCL-SABESP) pelas análises de MIB através de cromatografia gasosa associada a espectrômetro de massa (GC-MS-PAT).

\section{REFERÊNCIAS}

APHA, AWWA, WEF. Standard Methods for the Examination of Water and Wastewater. EUA: 1998.

FERREIRA FILHO S.S. Otimização da Aplicação do CAP no Tratamento de Água Visando a Redução de Compostos Orgânicos Causadores de Odor e Sabor em Águas de Abastecimento. Revista Engenharia Sanitária e Ambiental, v. 1, n. 4, p. 131-43, Out/Dez. 1996.

FERREIRA FILHO S.S. Viabilidade de Oxidação de Compostos Orgânicos Causadores de Gosto e Odor em Águas de Abastecimento Através da Aplicação do Dióxido de Cloro. Departamento de Engenharia Hidráulica e Sanitária. 28p., Julho 2000.

FERREIRA FILHO S.S. Remoção de Compostos Orgânicos Causadores de Gosto e Odor em Águas de Abastecimentos: Modelação Matemática e Otimização do Processo de Adsorção em CAP para o Sistema Produtor do Guarapiranga. Tese de Livre Docência apresentada à Escola Politécnica da USP, 333 p, 2001.

FERREIRA FILHO, S.S., FERNANDES, A.N. Remoção de Compostos Orgânicos Causadores de Gosto e Odor em Aguas de Abastecimento: Aplicação de Carvão Ativado em Pó. In: 22。 CONGRESSO BRASILEIRO DE ENGENHARIA SANITÁRIA E AMBIENTAL, Joinville, 2003. 
GILLOGLY, T.E.T. et al. Effect of Chlorine on PAC's Ability to Adsorb MIB, Journal American Water Works Association, v.90, n.2, p.107-14, 1998.

GLAZE, W.H.; SCHEP, R.; CHAUNEY, W. Evaluating Oxidants for the Removal of Model Taste and Odor Compounds From a Municipal Water Supply. Journal American Water Works Association, n. 82, v. 5, p. 79-84, 1990.

LALEZARY, S.; PIRBAZARI, M.; MCGUIRE, M J. Oxidation of Five Earthy-Musty Taste and Odor Compounds. Journal American Water Works Association , v. 52, n. 3, p. 62-69, 1986a.

LALEZARY, S; PIRBAZARI, M.; MCGUIRE, M.J. Evaluating Activated Carbons for Removing Low Concentrations of Taste and Odor-producing Organics. Journal American Water Works Association, v. 78 , n. 11, p. 76-82, 1986b.
LALEZARY-CRAIG, S. Optimizing the Removal of Geosmin and 2-Methylisoborneol by Powdered Activated Carbon. Journal American Water Works Association, v. 80, n. 3, p. 73$80,1988$.

MARCHETTO, M. Otimização do Processo de Remoção de Compostos Orgânicos Causadores de Gosto e Odor em Água de Abastecimento por Processo de Adsorção em Carvão Ativado em Pó. Relatório FAPESP, 77p mais anexos, fev. 2004.

NAJM, I. N. et al. Effect of Particle Size and Background Natural Organics on the adsorption Efficiency of PAC. Journal American Water Works Association, v. 82, n. 1, p. 65-72, 1990.

NEREMBERG, R.; RITTMANN, B.E.; SOUCIE W.J. Ozone/Biofiltration for Removing $M I B$ and Geosmin. Journal American Water Works Association, n. 12, v. 92, p. 85-95, Dec. 2000.
Endereço para correspondência:

Sidney Seckler Ferreira Filho Escola Politécnica da Universidade de São Paulo

Departamento de Engenharia

Hidráulica e Sanitária

Av. Prof. Almeida Prado, Travessa 2, n.27I - Prédio de Engenharia Civil

Cidade Universitária

05508-900 - São Paulo - SP - Brasil

Tel: (I I) 309 I-5220 / 5444

Fax: (I I) 309 I-5423

E-mail: ssffilho@usp.br 